\title{
Identifying Dimensions of Business Continuity Plan from Common Expressions among Business Continuity Professionals
}

\author{
Ahmad Ghandour ${ }^{1}$ \\ ${ }^{1}$ College of Business Administration, Al Ain University of Science and Technology, Abu Dhabi, UAE \\ Correspondence: Ahmad Ghandour, College of Business Administration, Al Ain University of Science and \\ Technology, Abu Dhabi, UAE. Tel: 971-2-613-3563. E-mail: ahmad.ghandour@aau.ac.ae
}

Received: February 15, 2014

Accepted: March 10, $2014 \quad$ Online Published: May 6, 2014

doi:10.5430/ijba.v5n3p136

URL: http://dx.doi.org/10.5430/ijba.v5n3p136

\begin{abstract}
This study examines the key aspects that explain a business continuity plan (BCP) as perceived by professionals. I have initiated a discussion at LinkedIn group "Business Continuity Management \& Risk" in which 37 participants gave 58 comments. The discussion was initiated in order to identify shared and common expressions of collective experience among the business continuity $(\mathrm{BC})$ professionals with regards to BCP. A cluster analysis based on the Euclidean distance between the most frequent words in the participants' text corpus $(6,555)$, revealed that a BCP has two aspects: being prepared and planning. While the "planning" aspect revealed two clusters interpreted as the process and the exercise of the plan respectively, the "prepared" aspect of the plan is a single cluster interpreted as the planning effectiveness. The study concludes with the findings.
\end{abstract}

Keywords: business continuity plan, being prepared, hierarchical cluster analysis, operationalization, wordle, LinkedIn

\section{Introduction}

Disasters are becoming increasingly common in today's world disrupting businesses' operations which consequently making their survival more challenging. Businesses are becoming more concerned than before on drafting a business continuity plan (BCP). It is acknowledged among business continuity practitioners that a business is well prepared for disasters only if a business continuity plan (BCP) is in place. Creating a BCP, however, has its own challenges and many businesses are still struggling to create a robust plan that is effective and focused. This may be a self-reinforcing cycle in that many businesses have little knowledge of what BCP means, its goal and its components. Whilst the literature provides a useful foundation on BCP and its creation, much of the research has also focused on business preparedness and how businesses prepare for disasters. The two concepts BCP or preparedness are key terms in the business continuity industry but are still somewhat unclear or ill-defined. The two concepts are often equated or conflated and the literature lacks the connections between the two. "A plan or being prepared?" became an inquiry for this study. The purpose of this article is to shed light on this issue as perceived by professional in the field.

In the era of social media, LinkedIn is a social network that enables users to build their online communities. It is mainly used for professional networking. Professional are members of groups within LinkedIn. These groups are based on subjects, issues and location. Within a group a member can initiate a discussion or comment on an existing one. Participation is voluntary and a discussion can provide useful comments and a qualitative data will be generated. The flow of the discussion can be controlled and kept on track by the discussion generator. This method is a powerful forum of generating a brainstorming, collective discussion and issue exploration. It captures a complete picture of how professionals view the topic under discussion.

This study contributes to the existing literature on BCP with the result found from analysing data generated from a discussion which has been initiated on a group within LinkedIn. The discussion was titled "a plan or being prepared" and the group hosted the discussion was "Business Continuity Management \& Risk".

\section{Business Continuity Plan}

BCP has been defined in a variety of ways. There is currently no accepted definition for BCP. According to Business Continuity Institute's Glossary "Business continuity plan is a collection of procedures and information which is 
developed, compiled and maintained in readiness for use in the event of an emergency or disaster". Duncan et al. (2010), define a BCP as a tool that aids organisations in staying in business under extreme circumstances. Engemann and Henderson (2011) describe BCP as the central plan that documents continuity and recovery procedures during and after a crisis. Although somewhat different in their wordings, the underlying meanings of these explicit definitions are very similar in that first, the objective of BCP remains to handle threats and resume operation with minimum disruption time, second $\mathrm{BCP}$ is a product a business requires whenever there is a disruption such as a disaster. The goal is have a plan in the event of a problem to preserve the organisation so that it can continue to offer its service and in order for a plan to be useful, it must be created before an interruption occurs. Creating a plan is important and requires a serious commitment. According to Scarinci (2002), staffing, time and money are the three common concerns businesses usually have when developing a plan. In order to create a plan, planning has to be done. The act of Planning for business continuity has been given emphasis in the literature. It has been defined as the process of taking the steps to commit a plan to paper. Eisenhower, Ex American president once said plans are nothing, planning is everything. Winston Churchill has also his famous quote "plans are of little importance but planning is essential". These imply that a comprehensive planning is required to handle expected and unexpected disruptions and has the value of leading to an outcome. Planning according to Penrose (2000), is the root of all crisis management activities. The Disaster Recovery Journal defines planning in its business continuity glossary as a process of developing and documenting arrangements and procedures that enable an organisation to respond to an event that lasts for an unacceptable period of time and return to performing its critical functions after an interruption (BC glossary by DRJ). According to Mayor et al. (2008), planning is a concept that can be defined as any activity that has the potential to reduce the negative impact of disaster events. The outcome of these activities is a checklist can be used to assess the nature and the extent of preparedness activities undertaken by a business (Webb, Tierney, \& Dahlhamer, 1999). Indeed through planning a plan that defines a process to be followed in the event of a disaster is created. According to Engemann and Henderson (2011), BCP is intended to document an organisation's approach to manage recovery from disaster. It is the documentation of a user's guide for how to preserve an organisation.

Organisations, however, still introduce challenges for developing a BCP. According to Vargo and Seville (2011) crisis strategic planning is a synthesis of concepts related to crisis management and strategic planning. Although the strategic planning is a separate process that focuses on opportunities, $\mathrm{BC}$ planning is carried out in isolation and focuses on threats (Preble, 1997). Yet the two involve processes to formulate a plan, to implement this plan and evaluate its effectiveness as well as dealing with the uncertain future for which opportunities and threats are inherent (Burnett, 1998). Some authors agreed on the process of the planning activity as three steps. The first step is to build the plan. The second step is exercising the plan, and finally a business should review their plan to keep it up-to-date (Neil, 2005; Rike, 2003; Scarinci, 2002). While building the plan includes the process to formulate a plan, it also outlines the steps to take if a disaster occurs for the consequential business recovery. In the exercise step, the plan is tested through a drill with user participation which provides training to personnel. In the review step, plans should be periodically checked for updates and improvements.

The establishment of BCP, however, cannot guarantee the freedom from the effect of failure but can provide a method of dealing with failure to meet the organisation's defined priorities (CMI, 2010). In a recent survey, the Chartered Management Institute found organisations that activated their PCB have effectively reduced the impact of the disruption and helped speed up their return to normal operation (CMI, 2012).

\section{Preparedness}

The other term that has appeared in the literature and gained considerable interest among researchers and practitioners is preparedness. The increasingly devastating impact of disasters on organisational performance requires organisations to be prepared. Preparedness, often intended as business continuity, describes the organisation's pre-disaster efforts to be better prepared to withstand the anticipated disaster and recover. Previous research has suggested that pre-disaster efforts are the means of reducing negative disaster impacts (Dahlhamer \& Reshaur, 1996; Kroll, Landis, Shen, \& Stryker, 1991) as it results in a more effective response to disasters (Corey \& Deitch, 2011; Tierney \& Dahlhamer, 1997).

Similar to BCP, preparedness has been defined in a variety of ways with no accepted unified definition. While some researchers have referred to the pre-disaster effort as preparedness (Corey \& Deitch, 2011; Tierney \& Dahlhamer, 1997), others have it conceptualised as: prevention and mitigation (Engemann \& Henderson, 2011) or risk reduction, prevention and preparedness (MCEER, 2010). Nevertheless, these efforts describe business strategies for the resumption of operation according to predetermined priorities following a disaster. Hence, these conceptualisations can 'be thought of as any activity that has the potential to save lives, decrease property damage, and reduce the 
negative impacts of disaster events, including long-term interruptions of business operations' (Mayer et al., 2008: 15). In this regard, preparedness is intended as business continuity where planning is an essential component (Karim, 2011; Mayer et al., 2008; Penrose, 2000).

Research also shows that BCP hardly existed among small businesses (Boin \& McConnell, 2007; Vargo \& Seville, 2011). Instead, preparedness is defined as having taken one or more of a specified set of measures. Webb et al. (2002), argued that preparedness is largely aimed at improving emergency response (i.e. a short-term focus) and recommended a thorough planning for a more comprehensive preparedness list in order to have a positive impact on recovery.

Other researchers refer to preparedness as an end results as opposed to an activity that the organisation is involved with. Sheaffer and Mano-Negrin (2003: 575) define preparedness as 'a state of corporate readiness to foresee and effectively address . . . adverse circumstances that have the potential to inflict a multi-dimensional crisis, by consciously recognising and proactively preparing for its inevitable occurrence'. Although what it means for the organisation to be prepared is still nebulous, a preparedness program would be designed to safeguard the organisation against threats which can disrupt business operation (Castillo, 2005).

Runyan (2006) posited that being prepared for the worst may help organisations get through many crisis situations intact. According to Lindstedt (2012), preparedness is then measured in terms of resource (physical assets required to provide services), procedures (methods, practices, and instructions for taking action to recover services) and competencies (characteristics allowing individuals to function throughout recovery) in order to recover from a disaster. Thus preparedness in this regard involves not only practices and training to deal with the incident (Castillo, 2005) but also a program that includes the "what", the "how" and the "way" a business can continue services (Lindstedt, 2012). Castillo (2005), suggest model that combines preparedness and BCP for businesses in order to return to normal operation following a disaster.

\section{Method}

A post was initiated on the LinkedIn group "Business Continuity Management \& Risk" to stimulate a discussion on business continuity plan (BCP). The post received 58 comments from 37 members in the group. The profile of all participants is a business continuity related. Comments were collected forming the data to be analysed. The most frequent words were extracted. A hierarchical cluster analysis was then used to trace hierarchy of groups among a set of observations. The results of hierarchical clustering are usually presented in a tree diagram referred to as dendrogram which the visual representation of the distance at which clusters are combined. Cluster analysis was carried out with SPSS statistical software. By assuming that word frequency in the corpus is a continuous variable, the Euclidean distance single linkage is the suitable criterion to measure how far apart two words were.

\section{Results}

A text corpus of 6,555 words was generated from the discussion. A word cloud graph based on the text corpus was created using the online algorithm wordle developed by J. Feinberg (www.wordle.net). The graph displays words with font size correlated with their frequency in the text corpus. Figure 1 shows the result.

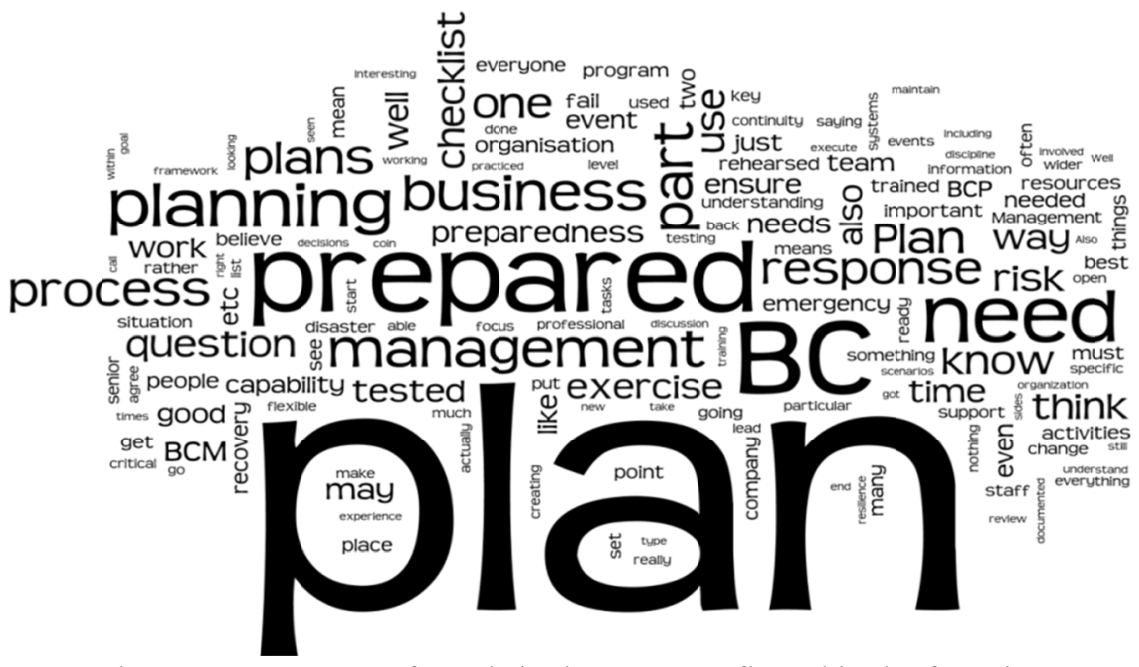

Figure 1. Frequency of words in the corpus reflected in the font size 
The most 20 frequent words in the text corpus was selected to conduct the cluster analysis: Plan (count 158), Prepared (count 42), Planning (count 25), BC (count 42), needs (count 47), exercising (count 21), management (count 20), plans, (count 21), response (count 17), process (count 22), failure (count 19), training (count 15), checklist (count 14), use (count 14), events (count 17), risks (count 14), means (count 13), teams (count 12). Tracing hierarchy of groups among a set of observation based on the Euclidean distance matrix between these 20 words reveal three main clusters. One cluster belongs to the prepare aspect of the plan interpreted as the planning effectiveness. The other two belong to the planning aspect of the plan, the first one is interpreted as the process of the plan and the second one is interpreted as the exercise of the plan. Figure 2 shows the cluster dendrogram based on the Euclidean distance matrix between the 20 most frequent words in the text corpus with the three clusters. Table 1 shows a detailed description of the resulting three clusters with some examples from the answers of the participants.

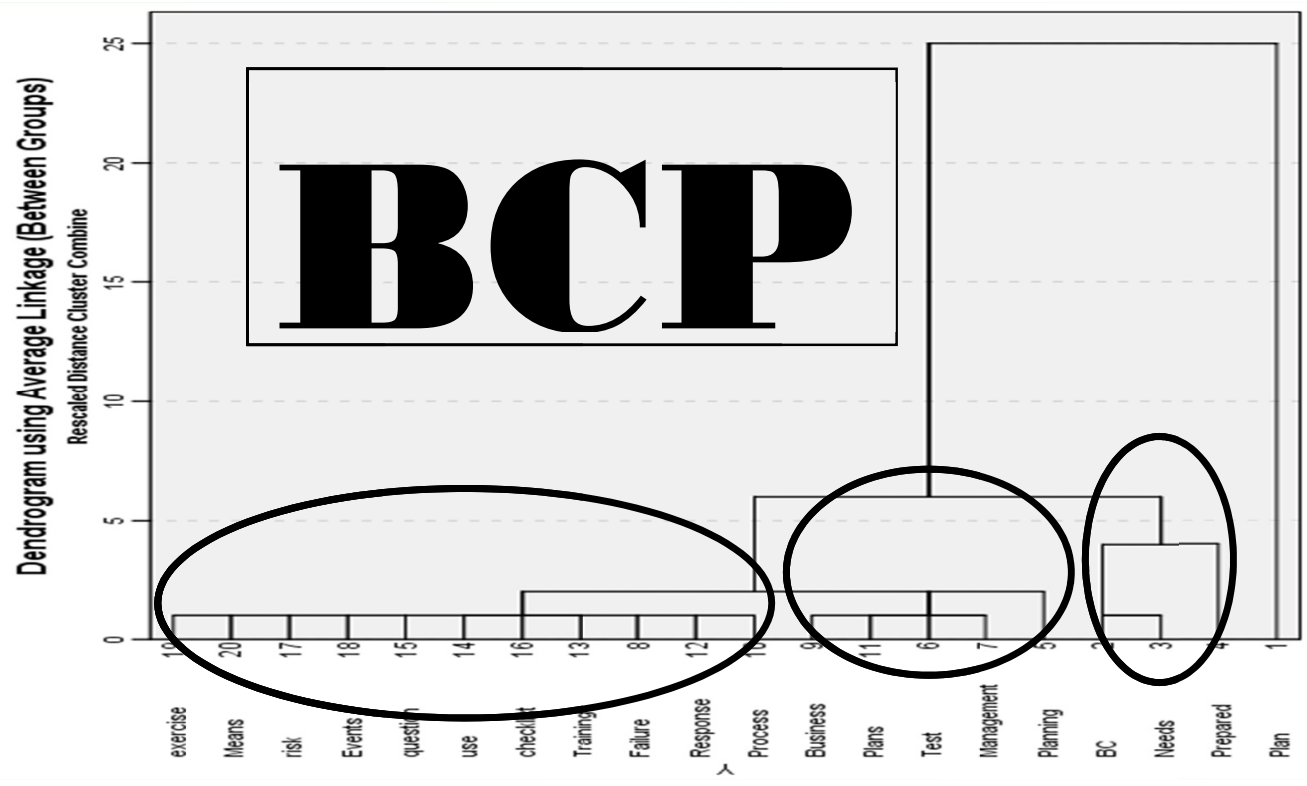

Figure 2. Cluster dendrogram

Table 1. Clusters, examples from the text and their interpretations

\begin{tabular}{|c|c|c|c|}
\hline Node & Cluster & Examples & Interpretation \\
\hline \multirow[t]{2}{*}{ Planning } & $\begin{array}{l}\text { Cluster 1: } \\
\text { Process, } \\
\text { response, use, } \\
\text { question, } \\
\text { events, risk, } \\
\text { means, failure, } \\
\text { training, } \\
\text { checklist }\end{array}$ & $\begin{array}{l}\text { Planning process should be taught to the people } \\
\text { involved so that they can complete the tasks needed to } \\
\text { do the job. } \\
\text { A checklist and a plan are the output of a planning } \\
\text { process. A plan documents the planning process and a } \\
\text { checklist identifies the business processes. }\end{array}$ & $\begin{array}{l}\text { Creating the plan: The words } \\
\text { forming this cluster point to the } \\
\text { process of creating a plan }\end{array}$ \\
\hline & $\begin{array}{l}\text { Cluster 2: } \\
\text { Test, Plans, } \\
\text { Management, } \\
\text { and business }\end{array}$ & $\begin{array}{l}\text { - A plan that's not been documented and tested is only a } \\
\text { strategy } \\
\text { - If you do not plan to do continuous, strenuous plan } \\
\text { testing to train team members as well as identify and } \\
\text { implement improvements, you will not have a } \\
\text { continuity capability }\end{array}$ & $\begin{array}{l}\text { Exercising the plan: The words } \\
\text { forming this cluster suggesting } \\
\text { the testing of the plan is a must }\end{array}$ \\
\hline Prepared & $\begin{array}{l}\text { Prepared, BC, } \\
\text { need }\end{array}$ & $\begin{array}{l}\text { - Preparedness is the destination } \\
\text { - Prepared is part of a plan and it is an aspect of } B C \\
\text { - The plan should contain guidance on what needs to be } \\
\text { done to prepare and how we continue to service the } \\
\text { customer. }\end{array}$ & $\begin{array}{l}\text { Planning effectiveness: The } \\
\text { words suggest the needs to } \\
\text { know of what is being done in } \\
\text { order to be prepared. }\end{array}$ \\
\hline
\end{tabular}




\section{Discussion}

In the present study we examined the perception of shared and common expressions of collective experience among $\mathrm{BC}$ professionals regarding $\mathrm{BCP}$. The results have also provided not only the interconnection between the two aspects but also a specific description of the perceived characteristics of each aspect. BCP was perceived as a needed asset for the organisation survival following a disaster. The present findings disentangled the main aspects that explain the constituent of a BCP. It is likely that the three described clusters (process, exercise and preparedness) reflect the dynamic of $\mathrm{BCP}$, its goal and its components.

The result provided that planning and being prepared are the two aspects of BCP. As put by one respondent "plan is a mean to an end". Planning reflects the "means" aspect of BCP while being prepared reflects the "end" aspect of BCP. The "means" aspect is represented by the process and the exercise phases of the BCP and the "ends" aspect is represented by planning effectiveness.

\subsection{Planning}

It is the activity element of the $\mathrm{BCP}$ that is required not only to create a plan but also to exercise it in an on-going basis. Creating a plan requires sufficient detail regarding the deployment of appropriate strategies for the resumption of operations according to predetermined priorities. Further, creating the plan meets the auditory requirements and compliance needs. Exercising BCP will provide the management with assurance that their business has included all the necessary steps in the plan. Regular exercising and testing keep the BCP fresh and real.

\subsection{Prepared}

It is the outcome of the planning activity that makes the organisation ready to deal with adverse events.

While planning reflects the extent of developing a plan, prepared is focussed on the effectiveness of such a plan. $\mathrm{BCP}$ is therefore is an activity the effectiveness of which is that the organisation has undertaken is prepared to continue operation following a disaster. Figure 3 shows the dynamics of BCP. As put by one respondent: The plan is a point-in-time document produced (ideally) from the minds of those with responsibility to execute the plan under adverse conditions. Being prepared is a "state of being" that must be sustained to be meaningful.

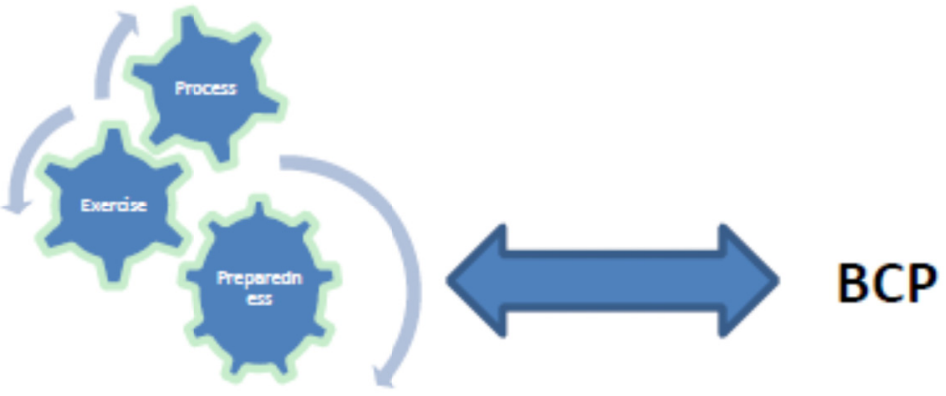

Figure 3. The dynamics of $\mathrm{BCP}$

The hierarchical structure of the dendrogram in Figure 2 shows more proximity between cluster 1 and cluster 2 . Hence preparedness is more effective with better planning. Better planning is achieved by following the process of creating a plan and the exercise of the plan.

\section{Conclusion}

The study involves the identification and linking the two salient dimensions that captures the means and ends of BCP. This multidimensional conceptualisation may be used to characterise BCP. The results indicate that BCP is an asset which leads organisations to be prepared through the conduct of planning so that they can resume their operation quickly after a disastrous event and avoid significant losses. This understanding would help businesses to have a plan. The study provides some interesting findings concerning the operationalization of BCP which can also be used as a diagnostic tool to assess an organisation's BCP activity. An organisation is said to be prepared when it undertakes the process of planning and exercise its plan. Thus, this study provides results for improving our understanding of the $\mathrm{BCP}$, for guiding future research, and for practitioners.

\section{References}

Boin, Arjen, \& McConnell, Allan. (2007). Editorial: Unravelling the Puzzles of Critical Infrastructures. Journal of Contingencies and Crisis Management, 15(1), 1-3. http://dx.doi.org/10.1111/j.1468-5973.2007.00499.x

Burnett, J.J. (1998). A strategic approach to managing crisis. Public Relations Review, 24(4), 475-484. http://dx.doi.org/10.1016/S0363-8111(99)80112-X 
Castillo, C. (2005). Disaster preparedness and business continuity planning at Boeing: An integrated model. Journal of Facilities Management, 3(1), 8-26. http://dx.doi.org/10.1108/14725960510808365

CMI. (2010). Business Continuity-Checklist 151. Retrieved 19 June 2012, from http://www.managers.org.uk/sites/default/files/u23/bcmPDF.pdf

CMI. (2012). Planning for the worst: the 2012 Business Continuity Management Survey. Retrieved 28 March 2012 , from http:/www.managers.org.uk/research-analysis/research/current-research/planning-worst-2012-business-continui ty-management-surve

Corey, C.M., \& Deitch, E.A. (2011). Factors Affecting Business Recovery Immediately after Hurricane Katrina. Journal of Contingencies and Crisis Management. http://dx.doi.org/10.1111/j.1468-5973.2011.00642.x

Dahlhamer, J.M., \& Reshaur, L. (1996). Businesses and the 1994 Northridge earthquake: An analysis of pre-and post-disaster preparedness. Paper presented at the Paper presented at the annual meeting of the Eastern Sociological Society, Boston, MA.

Duncan, W.J., Yeager, V.A., Rucks, A.C., \& Ginter, P.M. (2010). Surviving organizational disasters. Business Horizons, 54(2), 135-142. http://dx.doi.org/10.1016/j.bushor.2010.10.005

Engemann, K.J., \& Henderson, D.M. (2011). Business Continuity and Risk Management. Rothstien Association Inc., Publisher. Brookfield, Connecticut USA. Retrieved from www.rothstien.com

Karim, Akram Jalal. (2011). Business Disaster Preparedness: An Empirical Study for measuring the Factors of Business Continuity to face Business Disaster. International Journal of Business and Social Science, 2(18), 183-192.

Kroll, C.A., Landis, J.D., Shen, Q., \& Stryker, S. (1991). Economic impacts of the Loma Prieta earthquake:a focus on small business. Working Paper No. 91-187. University of California Transportation Center and the Center for Real Estate and Economics, University of California, Berkeley, CA.

Lindstedt, David. (2012). Measuring Preparedness and Predicting Recoverability. Retrieved 28 May 2012 , from http://busfin.osu.edu/FileStore/ECMP/Measuring\%20Preparedness\%20and\%20Predicting\%20Recoverability_V 1_Lindstedt.pdf

Mayer, B.W., Moss, J., \& Dale, K. (2008). Disaster and Preparedness: Lessons from Hurricane Rita. Journal of Contingencies and Crisis Management, 16(1), 14-23. http://dx.doi.org/10.1111/j.1468-5973.2008.00531.X

MCEER. (2010). PEOPLES: A framework for defining and measuring disaster resilience. Working Paper.

Neil, J. (2005). The disaster survival process. IEEE Engineering Management Review, 33(3), 110. http://dx.doi.org/10.1109/EMR.2005.26771

Penrose, J.M. (2000). The role of perception in crisis planning. Public Relations Review, 26(2), $155-171$. http://dx.doi.org/10.1016/S0363-8111(00)00038-2

Preble, J.F. (1997). Integrating the crisis management perspective into the strategic management process. Journal of Management Studies, 34(5), 769-791. http://dx.doi.org/10.1111/1467-6486.00071

Rike, B. (2003). Prepared or not... that is the vital question: when unplanned events or full-blown disasters strike, RIM professionals must have a strategy to ensure survival and at a cost that organizations can afford. Information Management Journal, 37(3), 25-32.

Scarinci, C. (2002). Contingency Planning for Small Businesses. The CPA Journal, 72(8), 65.

Sheaffer, Z. (2003). Mano-Negrin R. Executives' Orientations as Indicators of Crisis Management Policies and Practices. Journal of Management Studies, 40(2), 573-606. http://dx.doi.org/10.1111/1467-6486.00351

Tierney, K.J., \& Dahlhamer, J.M. (1997). Business disruption, preparedness and recovery: Lessons from the Northridge earthquake.

Vargo, J., \& Seville, E. (2011). Crisis strategic planning for SMEs: finding the silver lining. International Journal of Production Research, 49(18), 5619-5635. http://dx.doi.org/10.1080/00207543.2011.563902

Webb, G.R., Tierney, K., \& Dahlhamer, J.M. (1999). Businesses and disasters: Empirical patterns and unanswered questions.

Webb, G.R., Tierney, K.J., \& Dahlhamer, J.M. (2002). Predicting long-term business recovery from disaster: a comparison of the Loma Prieta earthquake and Hurricane Andrew. Global Environmental Change Part B: Environmental Hazards, 4(2-3), 45-58. http://dx.doi.org/10.1016/S1464-2867(03)00005-6 